\title{
BMJ Open Continuity of care and delivery of diabetes and hypertensive care among regular users of primary care services in Chile: a cross-sectional study
}

\author{
Javiera Leniz (1) , Martin C Gulliford
}

To cite: Leniz J, Gulliford MC. Continuity of care and delivery of diabetes and hypertensive care among regular users of primary care services in Chile: a cross-sectional study. BMJ Open 2019;9:e027830. doi:10.1136/ bmjopen-2018-027830

- Prepublication history and additional material for this paper are available online. To view these files, please visit the journal online (http://dx.doi. org/10.1136bmjopen-2018027830).

Received 09 November 2018 Revised 29 March 2019 Accepted 24 June 2019

Check for updates

(C) Author(s) (or their employer(s)) 2019. Re-use permitted under CC BY-NC. No commercial re-use. See rights and permissions. Published by BMJ.

School of Population Health and Environmental Sciences, King's College London, Faculty of Life Sciences and Medicine, London, UK

Correspondence to

Dr Javiera Leniz;

javiera.martelli@kcl.ac.uk

\section{ABSTRACT}

Objectives Explore factors related to continuity of care and its association with diabetes and hypertensive care, and disease control.

Design Cross-sectional study.

Setting Data from the Chilean Health National Survey 2009-2010.

Participants Regular users of primary care services aged 15 or older.

Primary and secondary outcome measures Proportion of hypertensive and diabetic patients with a blood pressure $<140 / 90 \mathrm{~mm} \mathrm{Hg}$ and $\mathrm{HbA} 1 \mathrm{c}<7.0 \%$ respectively, self-report of diagnosis, treatment and recent foot and ophthalmological exams. Associations between continuity of care, sociodemographic characteristics, and primary and secondary outcomes were explored using logistic regression.

Results 3887 primary care service users were included. $14.7 \%$ recognised a usual GP, $82.3 \%$ of them knew their name. Continuity of care was positively associated with age $>65$ years ( $0 \mathrm{R} 4.81,95 \% \mathrm{Cl} 3.16$ to 7.32 ), being female (OR 1.66, 95\% Cl 1.34 to 2.05), retired (OR 2.22, $95 \% \mathrm{Cl} 1.75$ to 2.83 ), obese (OR $1.66,95 \% \mathrm{Cl} 1.29$ to 2.14), high cardiovascular risk $(\mathrm{OR} 2.98,95 \% \mathrm{Cl} 2.13$ to 4.17) and widowed (OR $1.50,95 \% \mathrm{Cl} 1.13$ to 1.99$)$, and negatively associated with educational level (8-12 vs $<8$ years $0 \mathrm{R} 0.79,95 \% \mathrm{Cl} 0.64$ to 0.97 ), smoking (OR $0.65,95 \% \mathrm{Cl} 0.52$ to 0.82 ) and physical activity (OR 0.76 $95 \% \mathrm{Cl} 0.61$ to 0.95$)$. Continuity of care was associated with diagnosis awareness (OR 2.83, 95\% $\mathrm{Cl} 1.21$ to 6.63$)$, pharmacological treatment (OR $2.04,95 \% \mathrm{Cl} 1.15$ to 3.63$)$ and a recent foot (OR $3.17,95 \% \mathrm{Cl} 1.84$ to 5.45$)$ and ophthalmological exam (OR $3.20,95 \% \mathrm{Cl} 1.66$ to 6.18$)$ in diabetic but not in hypertensive patients.

Conclusions Continuity of care was associated with higher odds of having a recent foot and ophthalmological exam in patients with diabetes, but not with better diseases control. Findings suggest patients with chronic conditions have better continuity of care access.

\section{BACKGROUND}

Chronic diseases and long-term conditions, including cancers and circulatory diseases, account for $19 \%$ of the global burden of disease, followed closely by mental disorders. ${ }^{1}$ Despite the availability of effective treatment,
Strengths and limitations of this study

First study that explores continuity of care and its relationship with health outcomes in Chile.

- The study uses a nationally representative population-based sample.

- The data used combine clinical and sociodemographic variables.

- The cross-sectional design of this study does not allow to attribute causal relationships.

- Some self-reported variables might be affected by recall bias.

a significant proportion of patients do not achieve adequate levels for disease control measures. ${ }^{2-5}$ Effective preventive medical interventions are available for reducing the risk of complications and cardiovascular diseases. ${ }^{6-8}$ Several authors have highlighted the role of the health system structure in the achievement of optimal outcomes for chronic diseases, especially in primary care ${ }^{9-12}$ One of the main attributes of a primary care-oriented service is the long-term person-focused care. $^{11-13}$

Continuity of care can be defined as a long-term relationship between physicians and patients. ${ }^{14} 15$ It has been associated with greater patient satisfaction, improved uptake of preventive services, lower rates of hospitalisation and emergency department visits and lower mortality rates. ${ }^{16-20}$ Results from research focused on patients with chronic conditions suggest that continuity of care is correlated with fewer visits to emergency departments and better glycosylate haemoglobin (HbAlc) control in diabetic patients. ${ }^{21}$ However, the evidence regarding the impact of continuity of care on healthcare outcomes is based mainly on studies from USA, Canada or European countries. There is, therefore, an important gap of information regarding continuity of care in other settings. Due to 
the nature of the concept of continuity of care and the cultural differences that might determine patients and doctors' expectations about healthcare, evidence from developed countries might not be applicable in low-income contexts.

Chile is an OECD (Organisation for Economic Co-operation and Development) country where the burden of disease is similar to that observed in countries that are in an advanced stage of the epidemiological transition. Ischaemic heart diseases and stroke are the leading causes of death in the population, followed closely by cancer. ${ }^{22}$ Even though continuity of care has been identified as a major challenge in Chile, ${ }^{23}{ }^{24}$ there are no studies assessing the level of relational continuity of care in the health system and their impact on clinical outcomes. The aim of this research is to explore factors related with different levels of continuity of care measured and its association with delivery of diabetes and hypertensive care and disease control in regular users of primary care in Chile.

\section{METHODS}

This cross-sectional study drew on data from the last Health National Survey (HNS) performed in Chile.

\section{The Chilean Health National Survey 2009-2010}

The second version of the Health National Survey was conducted in 2009 and commissioned by the Ministry of Health. The survey was designed to be nationally representative; individuals from the general population from 15 years old and older were included. The sample of the HNS 2009 was a multistage sample of households and disproportionately stratified by geographic region and urban/rural area, using the Census population as a frame. The response rate was $75.3 \%$, and the loss rate after the recruitment was $8.7 \%$. The final survey sample size includes 5293 individuals. Survey instruments included 42 health problems, five physiological measurements and 17 biochemical measurements. ${ }^{25}$

The survey participants were interviewed in their homes, with an average of two home visits per individual. During the first home visit, they were invited to participate, signed the informed consent and answered a validated questionnaire administrated by trained interviewers. Questions regarding whether individuals had been diagnosed with hypertension or diabetes, were receiving treatment for hypertension or diabetes and have had a foot and ophthalmological exam were included in the questionnaire. During the second home visit, a trained nurse collected blood and urine samples. Blood glucose and glycosylated haemoglobin (HbAlc) were estimated from that sample. Participants were asked during the first visit to not eat any food 11 hours prior the second visit and participants with a diagnosis of diabetes were scheduled for the first visit in the morning. During this second visit, anthropometric measures were taken, including height, weight and blood pressure. Three measurements of blood pressure were obtained, prior to $5 \mathrm{~min}$ resting and with an interval of
$2 \mathrm{~min}$ between each measurement. An automatic pressure sphygmomanometer was used (Omron HEM 742). ${ }^{25}$

\section{Population and sample}

For this study, only patients with public insurance were analysed because the questions regarding continuity of care were asked only to regular users of primary care services delivered by the government, which corresponds to $80 \%$ of the overall population in the survey. Individuals were considered as having hypertension if they had a mean systolic blood pressure higher than $140 \mathrm{~mm} \mathrm{Hg}$ and/or a mean diastolic blood pressure higher than $90 \mathrm{~mm} \mathrm{Hg}$ or were receiving pharmacological treatment at the time of the survey. Individuals were considered as having diabetes mellitus if they had fasting blood glucose higher than $126 \mathrm{mg} / \mathrm{dL}$ or reported that they had been diagnosed with diabetes before the visit.

A sample size was calculated for diabetes control and systolic blood pressure as the main outcomes. The study had more than $80 \%$ power to detect ORs of 1.5 and above.

\section{Instruments and measurements \\ Continuity of Care}

Two questions were used to assess the level of continuity of care among participants. The first one was 'Do you have your 'own' general doctor or family doctor? The question specified in brackets that a general practitioner (GP) is the one they can appeal to solve the majority of their health problems. The second question asked whether or not individuals who referred having an 'own doctor' also knew the name of that doctor. A measure of continuity of care was constructed from these two questions. Three categories of continuity of care were considered. First, individuals who reported having a GP whose name they know. Second, individuals who report having a GP, but do not know his/her name. And finally, individuals who do not have a particular GP.

\section{Primary and secondary outcome variables}

The primary outcomes were the proportion of hypertensive patients with a systolic and diastolic blood pressure less than $140 \mathrm{~mm} \mathrm{Hg}$ and $90 \mathrm{~mm} \mathrm{Hg}$ respectively, and the proportion of diabetic patients with an $\mathrm{HbAlc}<7.0 \%$ (53 $\mathrm{mmol} / \mathrm{mol})$.

Hypertension and diabetes care was assessed using the self-reported questions from the questionnaire. The proportion of individuals who referred having received a diagnosis of hypertension or diabetes and the proportion of individuals who referred having received treatment were included as secondary outcomes, as well as the proportion of diabetic patients who referred having had a foot examination in the last year, and an ophthalmological exam in the last 2 years.

\section{Co-variables}

Cardiovascular risk was calculated from data related to the individual's age, cholesterol level, smoking status and blood pressure using the Framingham equation. Individuals with a probability of having a cardiovascular event 
less than $10 \%$, between $10 \%$ and $20 \%$ and more than $20 \%$ in 10 years, were considered as having a low, high and very high cardiovascular risk respectively. The Spanish version of the global physical activity questionnaire (GPAQ) was used. The GPAQ considers three domains of physical activity: at work, while commuting and during recreational activity. The sum of the three activities determines the level of physical activity of an individual. A tobacco exposure module was included in the first visit that considered basic questions about smoking, based on the minimum instrument (core questions) surveillance smoking used by the Pan-American health organization. The questions identified two categories: current smoker (daily and occasional) and former smoker.

\section{Analysis}

A descriptive analysis was performed for all variables included in the study according to the level of continuity of care. Univariate analysis using logistic regression was performed to evaluate the association between continuity of care and categorical variables. An Analysis of Variance (ANOVA) test was performed to analyse the association between continuous variables with continuity of care. Demographic variables that were associated with both continuity of care and the outcomes were considered as possible confounders and were therefore used to fix the model for multivariate analysis. A multivariate logistic regression analysis was used to explore the relationship between the level of continuity of care and the different outcomes, adjusting for confounders. A backward approach was used to fix the multivariate logistic regression. All variables that were related to continuity of care and the respective outcome were included in the first model. Explanatory variables were kept in the model based on a priori hypothesis and significance in multivariate analysis $(p$ value $<0.2)$. Individuals that did not respond to the question 'Do you have a family physician or GP?' were excluded from the analysis. The 3.5.0 version of the statistical software $\mathrm{R}$ was used for the analysis.

\section{Patient and public involvement}

Patient or public were not involved in this study.

\section{RESULTS}

A total of 4264 individuals from the Health National Survey reported having a public insurance and were selected for the current study. Among them, 3887 individuals responded to the question 'Do you have you a family physician or GP?', and therefore, 377 individuals were excluded and considered as missing values (online supplementary file 1$)$.

There were $572(14.7 \%)$ of the individuals included in the Health National Survey who affirmed having a GP as a usual doctor, and $471(82.3 \%)$ of these affirmed knowing the name of their doctor (table 1). Individuals who indicated having a GP as a usual doctor and knowing their name had greater odds of age greater than 65 years
(OR 4.81, 95\% CI 3.16 to 7.32), female gender (OR 1.66, $95 \%$ CI 1.34 to 2.05 ), being widowed (OR $1.50,95 \%$ CI 1.13 to 1.99 ), being retired (OR 2.22, 95\% CI 1.75 to 2.83), having a high (OR 1.88, 95\% CI 1.53 to 2.32) or very high cardiovascular risk (OR 2.98, 95\% CI2.13 to 4.17 ), or having a body mass index $>30$ (OR $1.66,95 \%$ CI 1.29 to 2.14). Individuals with more than 8 years of education, single people and those with moderate and high level of physical activity were less likely to mention having a GP as a usual doctor. Recognising the name of their regular doctor was also highly associated with cardiovascular risk factors, with lower odds of having a high level of physical activity, greater odds of being obese or having a diagnosis of diabetes or hypertension. Having a regular doctor was not associated with rurality or household income (table 1).

A total of 418 (10.8\%) diabetic and 1252 (32.2\%) hypertensive individuals were identified in the survey. Among individuals classified as having diabetes, $324(78.6 \%)$ were aware of a diabetes diagnosis, and $234(56.0 \%)$ were receiving pharmacological treatment at the time of the survey. Among individuals classified as having hypertension, $891(71.2 \%)$ were aware of a hypertension diagnosis, and $565(45.1 \%)$ were receiving pharmacological treatment at the time of the survey.

There were $90(21.5 \%)$ diabetic patients that referred to having a usual GP. Continuity of care was not associated with optimal levels of glycaemic control (table 2). Individuals that had a personal GP and knew their name were 2.04 (95\% CI 1.15 to 3.63) more likely to be receiving pharmacological treatment for diabetes and $2.83(95 \%$ CI 1.21 to 6.63 ) more likely of being aware of their diagnosis than individuals without a usual GP, after adjusting for confounders. They were also more likely to have had a recent foot exam (OR 3.17, 95\% CI 1.84 to 5.45) and a recent ophthalmological exam (OR 3.2, 95\% CI 1.66 to 6.18 ) than individuals without a usual GP.

There were $258(20.6 \%)$ hypertensive patients that referred to having a usual GP. Continuity of care was not associated with being more aware of their diagnosis, receiving pharmacological treatment or better blood pressure control for these patients (table 2).

\section{DISCUSSION}

\section{Summary of findings}

This study evaluated continuity of care and its relationship with health outcomes in the Chilean public health sector. Continuity of care in this study was positively associated with age, sex, occupation, nutritional, cardiovascular risk and marital status and negatively associated with educational level, smoking and physical activity. Patients with diabetes or hypertension diagnosis were more likely to know the name of their usual GP. In diabetic patients, continuity of care was associated with receiving treatment and being aware of diabetes diagnosis, and higher odds of having a recent foot and ophthalmological exam. In hypertensive patients, continuity of care was 
Table 1 Univariate association between level of continuity of care and categorical variables.

Do you have your family doctor?

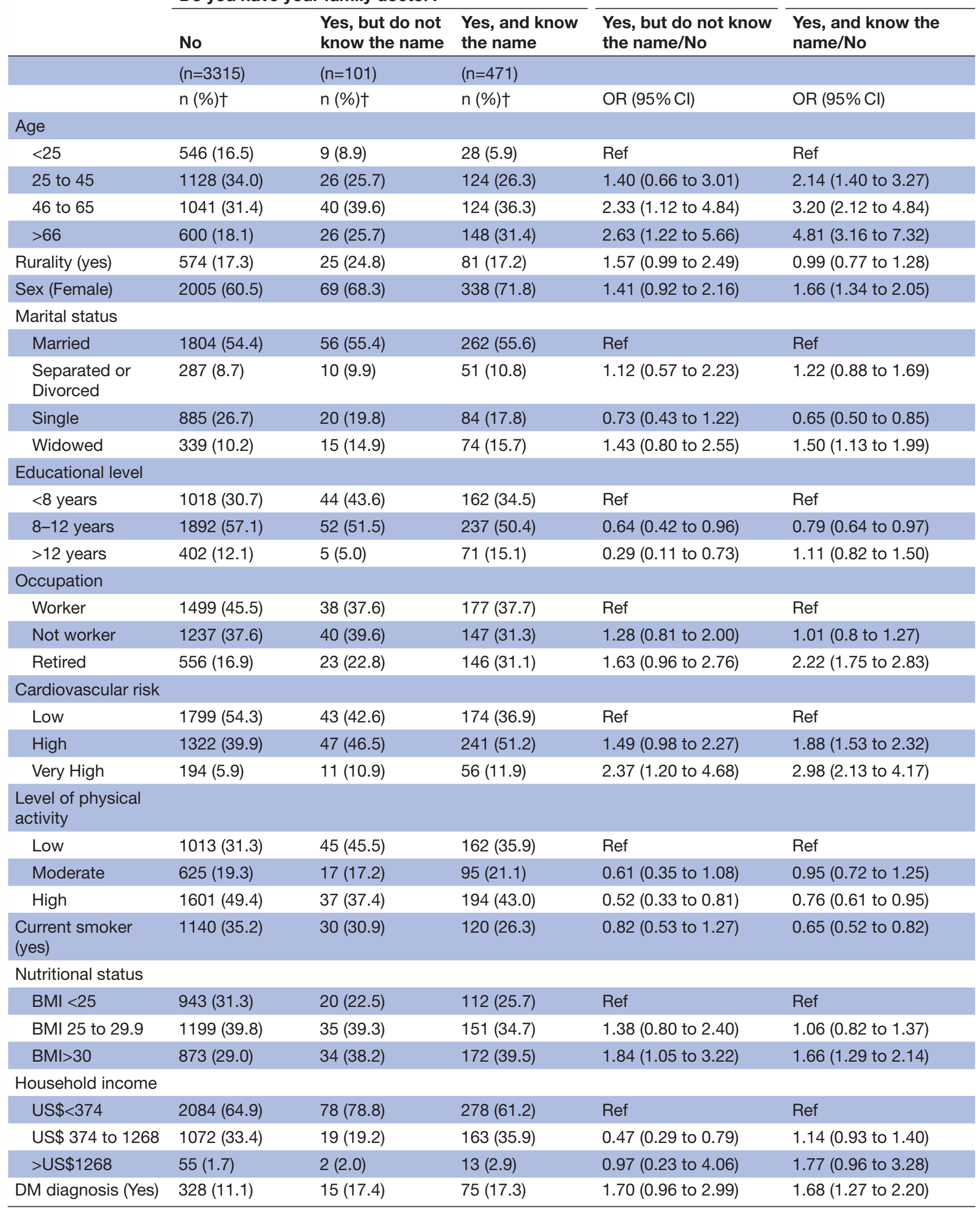

Continued 


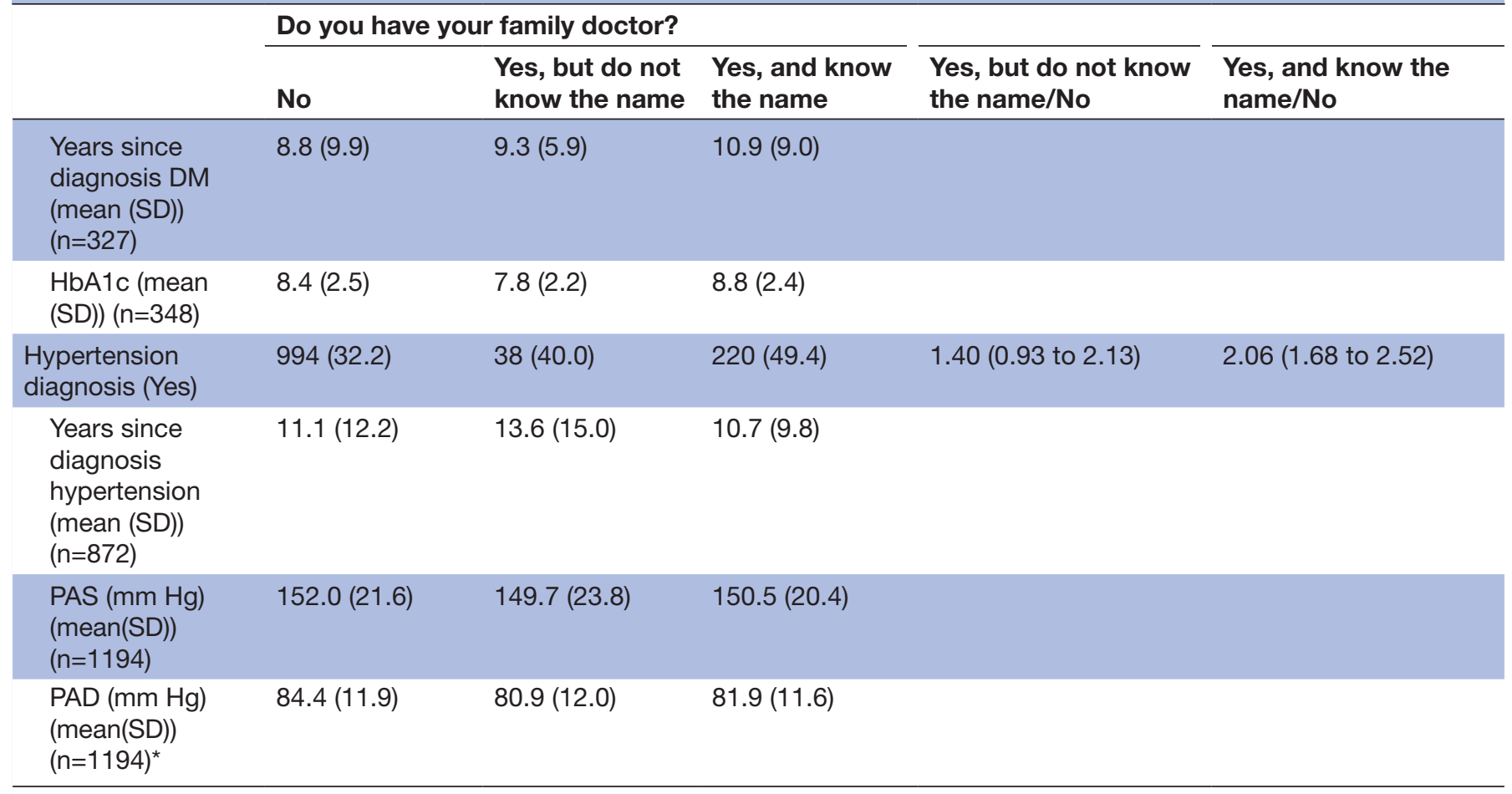

${ }^{*}$ ANOVA p-value $<0.01$.

†Column per cent.

BMI, body mass index; DM, diabetes mellitus; HbA1c, glycosylate haemoglobin; PAD, Diastolic Blood Pressure; PAS, Systolic Blood Pressure; Ref, reference.

not associated with higher odds of being aware of their diagnosis, receiving pharmacological treatment or better levels of blood pressure control.

Individuals that knew the name of their usual GP were more likely to be retired, widowed and older, which might have some implications regarding access to healthcare. People without a regular job might have more time to ask for an appointment or attend medical appointments. However, it is likely that being retired is also associated with age and chronic conditions. It is also possible that older adults might have a greater preference for having a usual GP and they consequently make efforts to achieve a better continuity of care. Individuals who knew the name of their usual GP were more likely to have high cardiovascular risk factors, such as having a diagnosis of diabetes, hypertension, obesity and lower levels of physical activity. This association could be explained because healthcare provision is usually based on need, and therefore, patients with chronic conditions tend to have better access to healthcare and visit their doctor more regularly than other non-chronic patients. However, in absolute terms, only around $20 \%$ of patients with diabetes and hypertension in this study referred to know the name and having a regular doctor.

Diabetic patients that referred to have a usual GP and knowing the name of their doctor were 3.17 times (95\% CI 1.84 to 5.48 ) more likely to have had a foot examination in the last year and 3.2 times (95\% CI 1.66 to 6.18 ) more likely to have had an ophthalmological examination in the last 2 years. These findings are consistent with those found in two other studies, ${ }^{26}{ }^{27}$ and suggest patients with a better continuity of care might receive better quality of care. Consultations with the same physician over time might contribute to having better coordination of care, and therefore might facilitate the delivery of appropriate and timely preventive services for diabetes care. Nevertheless, it is not possible to rule out the possibility of a spurious association between foot examination, ophthalmological exam and continuity due to recall bias. The uptake of both services in this study was assessed through individuals' self-report. Patients with a usual GP could have a different care-seeking pattern that predisposes them to be more concerned about their health and therefore remembered more easily whether they have had a foot examination or not, compared with patients without a usual provider. A more objective measure of foot and ophthalmological exam, such as information from administrative data, could help to assess the possibility of recall bias.

This study failed to prove an association between continuity of care and better patients outcomes such as diabetes and hypertension control. This probably could be explained because healthcare centres prioritise appointments and follow-ups for patients with poor clinical outcomes to improve their management. However, the cross-sectional design of this study does not allow to 
Table 2 Univariate and multivariate logistic regression between relational continuity of care and cardiovascular outcomes.

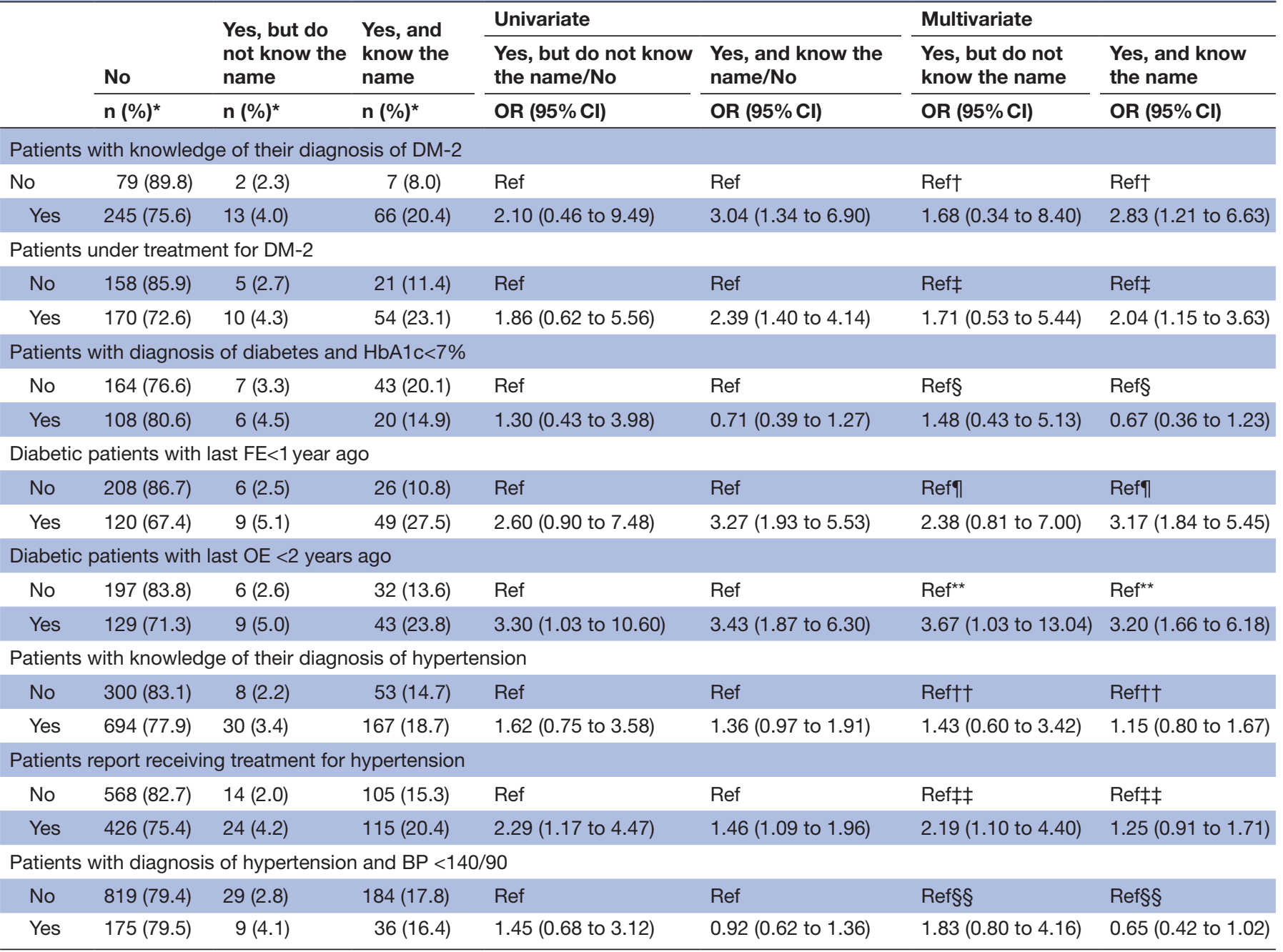

${ }^{*}$ Row per cent.

†Adjusted for age, sex, marital status, physical activity and smoking status.

$\ddagger$ Adjusted for age, sex, marital status, educational level and smoking status.

$\S$ Adjusted for age, sex, smoking status and BMI.

TAdjusted for age, sex, marital status and occupation.

${ }^{* *}$ Adjusted for age, sex, occupation and BMI.

††Adjusted for age, sex, marital status, educational level, BMI, smoking status and occupation.

$\ddagger \ddagger$ Adjusted for age, sex, marital status, educational level, occupation and smoking status.

$\S \S$ Adjusted for age, sex, marital status, educational level, BMI and physical activity.

BMI, body mass index; BP, blood pressure; DM-2, diabetes mellitus type 2; FE, foot examination; HbA1c, glycosylate haemoglobin; OE

ophthalmological examination; Ref, reference.

attribute a causal relationship to this association. These results are consistent with those found in Gulliford et $a l^{28}$ and O'Connor $e t a l,{ }^{27}$ where experienced continuity of care was not associated with the level of HbAlc. But they differ from those obtained in two other observational studies where individuals with a usual provider had 6.69 more chances to have an HbA1C level below $7 \%,{ }^{29}$ or better continuity score was statistically associated with lower levels of HbAlc. ${ }^{30}$ Results from these studies are difficult to compare due to the fact that they used different measurements for continuity of care, as well as different methodologies.

The fact that some individuals know or do not know the name of their usual doctor, could be perceived as constituting different levels of continuity of care, assuming that patients who know the name of their doctors have a stronger relationship with them. However, the results fail to show any gradient effect among the different levels of continuity of care used in the study. These results might be explained by the low number of individuals belonging to that category. Only $101(2.6 \%)$ persons in the sample referred to having their GP but not knowing his/her name.

The proportion of individuals that referred to having a usual GP in this sample was unusually low (14.7\%). Studies from USA and the UK have reported much higher rates of having a regular doctor, between $44 \%$ and $86 \% .^{29} 3132$ While there might be methodological differences that can explain these disparate results, it is highly possible 
that these discrepancies can be explained by differences in the structure and resources of the healthcare system among countries. Chile reported a rate of 1.87 physicians per 1000 population in 2013, in contrast with 3.72 and 3.3 per 1000 population in the UK and USA respectively. ${ }^{33}$ Therefore, it is possible that the lower density of physicians in the country hinders the ability to maintain an adequate continuity of care, giving priority to maintaining adequate access to healthcare. In addition, differences in healthcare resources and treatments in different settings might limit the generalisability of these findings.

\section{Strengths and limitations}

The measure of continuity of care used in the study has some limitations that can account for these results. Patients' report of provider affiliation does not capture the length and strength of that relationship, which seems to be a major dimension of continuity of care. Additionally, recognising a usual provider does not necessarily imply frequent consultations or real contact with the provider, nor the quality of care provided, factors that could be substantial in improving health outcomes. Many other measures of continuity of care have been described in the literature. Nevertheless, no other single measure has proven to be superior to the others or capture the whole concept of continuity of care. The measure of continuity used in this analysis has the advantage of considering the patient's perspective and of being easy to implement and simple to understand and has been widely employed in the literature allowing comparisons with other studies. ${ }^{34-38}$

As in any observational epidemiological study, unmeasured confounders might have biassed the associations found in this study. Patients with better continuity of care were more likely to have being receiving pharmacological treatment for their disease. The cross-sectional design of this study cannot rule out the possibility that patients with a diagnosis of diabetes and hypertension had a better continuity of care as a consequence of the process of monitoring the disease treatment, due to lack of temporality in the measurement of both variables. We did not have information about the type of treatment each patient was receiving or the appropriateness of that treatment and therefore, it was not possible to account for the fact that some individuals might have been receiving pharmacological schemes that might be more effective to achieve control of the disease. We did not have either information on physicians' characteristics that might influence the quality of care received by patients.

\section{CONCLUSIONS}

Continuity of care was associated with higher odds of having a recent foot and ophthalmological exam in patients with diabetes, but not with better diseases control. Differences in the age and occupation among individuals with a regular GP might be related to the presence of a chronic condition. Findings suggest patients with chronic conditions have better access to continuity of care.

Results showed an association between continuity of care and the proportion of diabetic users of the public health services in Chile receiving treatment for their diseases. However, by measuring both, the dependent and independent variables at the same time, it is not possible to rule out the possibility of reverse causation.

Only a minority of participants in this survey referred to have a regular doctor. However, the majority of them are also able to identify their doctor's name. It would be recommendable to explore strategies that might improve the level of continuity of care experienced by users of the public healthcare sector in Chile, such as incentives to improve the availability of physicians in the public sector and reducing the practice size.

Further investigation that incorporates a longitudinal approach would be necessary to clarify whether or not continuity of care has an impact on healthcare outcomes in Chile.

Acknowledgements The authors would like to acknowledge the support provided by the Epidemiology Department from the Ministry of Health in Chile, by facilitating the access to the database of the National Health Survey 2009-2010 and in particular, to Dr. Dario Lopez. I would like to express my special gratitude to Dr. Paula Margozzini from the Public Health Department at the Pontifical Catholic University of Chile, for providing the contact with the National Health Survey team, facilitating the access to the Survey questionnaires and her technical support with some specific aspects of the Survey.

Contributors $\mathrm{JL}$ contributed to the design, data analysis, interpretation and writing of first and subsequent drafts of the paper. MCG contributed to the design, data analysis, interpretation and comments on the first and subsequent drafts of the paper.

Funding JL was funded by CONICYT, Programa Formacion de Capital Humano Avanzado, Magister Becas Chile, 2015, Folio 73161335.

Competing interests None declared.

Patient consent for publication Not required.

Ethics approval The Health National Survey 2009-2010 was approved by the Pontifical Catholic University of Chile Ethic Committee and the Ministry of Health on 2009. The authors of the study confirmed that they had guarded the autonomy and confidentiality of patients. The database is anonymised, and therefore there is no access to the identity of the participants. Furthermore, this study does not consider additional data collection. In consideration of that, this study does not require additional ethical approval.

Provenance and peer review Not commissioned; externally peer reviewed.

Data availability statement Data may be obtained from a third party and are not publicly available. The data that support the findings of this study are available from the Epidemiology Department, Ministry of Health in Chile but restrictions apply to the availability of these data, which were used under license for the current study, and so are not publicly available.

Open access This is an open access article distributed in accordance with the Creative Commons Attribution Non Commercial (CC BY-NC 4.0) license, which permits others to distribute, remix, adapt, build upon this work non-commercially, and license their derivative works on different terms, provided the original work is properly cited, appropriate credit is given, any changes made indicated, and the use is non-commercial. See: http://creativecommons.org/licenses/by-nc/4.0/.

ORCID iD

Javiera Leniz http://orcid.org/0000-0002-9315-4871

\section{REFERENCES}

1 Murray CJL, Vos T, Lozano R, et al. Disability-adjusted life years (DALYs) for 291 diseases and injuries in 21 regions, 1990-2010: a 
systematic analysis for the global burden of disease study 2010 . The Lancet 2012;380:2197-223. 10.1016/s0140-6736(12)61689-4 [published Online First: 2012/12/19].

2 de Pablos-Velasco P, Parhofer KG, Bradley C, et al. Current level of glycaemic control and its associated factors in patients with type 2 diabetes across Europe: data from the Panorama study. Clin Endocrinol 2014;80:47-56.

3 Egan BM, Li J, Qanungo S, et al. Blood pressure and cholesterol control in hypertensive hypercholesterolemic patients: National health and nutrition examination surveys 1988-2010. Circulation 2013;128:29-41. 10.1161/circulationaha.112.000500 [published Online First: 2013/07/03].

4 Fox KM, Gerber PharmD RA, Bolinder B, et al. Prevalence of inadequate glycemic control among patients with type 2 diabetes in the United Kingdom general practice research database: a series of retrospective analyses of data from 1998 through 2002. Clin Ther 2006;28:388-95. 10.1016/j.clinthera.2006.03.005 [published Online First: 2006/06/06]

5 Kontopantelis E, Springate D, Reeves D, et al. Withdrawing performance indicators: retrospective analysis of general practice performance under UK quality and outcomes framework. BMJ 2014;348. 10.1136/bmj.g330 [published Online First: 2014/01/29].

6 American Diabetes Association. Standards of medical care in diabetes--2014. Diabetes Care 2014;37 Suppl 1:S14.

7 Dorresteijn JAN, Kriegsman DMW, Assendelft WJJ, et al. Patient education for preventing diabetic foot ulceration. Cochrane Database Syst Rev 2014;8.

8 Nelson KE, Hersh AL, Nkoy FL, et al. Primary care physician smoking screening and counseling for patients with chronic disease. Prev Med 2015;71:77-82. 10.1016/j.ypmed.2014.11.010 [published Online First: 2014/12/03]

9 Grembowski D, Schaefer J, Johnson KE, et al. A conceptual model of the role of complexity in the care of patients with multiple chronic conditions. Med Care 2014:52:S7-14. 10.1097/ mlr.0000000000000045 [published Online First: 2014/02/25].

10 Milani RV, Lavie CJ. Health care 2020: reengineering health care delivery to combat chronic disease. Am J Med 2015;128:337-43. 10.1016/j.amjmed.2014.10.047 [published Online First: 2014/12/03].

11 Starfield B, Shi L, Macinko J. Contribution of primary care to health systems and health. Milbank Q 2005;83:457-502. 10.1111/j.14680009.2005.00409.x [published Online First: 2005/10/06]

12 Wagner EH, Austin BT, Von Korff M, Korff MV. Organizing care for patients with chronic illness. Milbank Q 1996;74:511--44.

13 Starfield B. Primary care: an increasingly important contributor to effectiveness, equity, and efficiency of health services. SESPAS report 2012. Gac Sanit 2012;26 Suppl 1:20-6. 10.1016/j. gaceta.2011.10.009 [published Online First: 2012/01/24].

14 Gulliford M, Naithani S, Morgan M. What is 'continuity of care'? J Health Serv Res Policy 2006;11:248-50. 10.1258/135581906778476490 [published Online First: 2006/10/05]

15 Haggerty JL, Reid RJ, Freeman GK, et al. Continuity of care: a multidisciplinary review. BMJ 2003;327:1219-21. 10.1136/ bmj.327.7425.1219 [published Online First: 2003/11/25].

16 Cabana MD, Jee SH. Does continuity of care improve patient outcomes? J Fam Pract 2004:53:974-80.

17 Pereira Gray DJ, Sidaway-Lee K, White E, et al. Continuity of care with Doctors-a matter of life and death? A systematic review of continuity of care and mortality. BMJ Open 2018;8:e021161.. 10.1136/bmjopen-2017-021161 [published Online First: 2018/07/01]

18 Sandall J, Soltani H, Gates S, et al. Midwife-led continuity models versus other models of care for childbearing women. Cochrane Database of Systematic Reviews 2016;13. 10.1002/14651858. CD004667.pub5 [published Online First: 2016/04/29].

19 Saultz JW, Lochner J. Interpersonal continuity of care and care outcomes: a critical review. Ann Fam Med 2005;3:159-66.
20 Wasson JH, Sauvigne AE, Mogielnicki RP, et al. Continuity of outpatient medical care in elderly men. A randomized trial. JAMA 1984;252:2413-7.

21 Continuity of care to optimize chronic disease management in the community setting: an evidence-based analysis. Ontario health technology assessment series 2013;13:1--41.

22 DEIS. Estadisticas de Mortalidad. Departamento de Estadisticas E Informacion en Salud. Gobierno de Chile 2014.

23 Orrego C, Arancibia A, Contreras JL, et al. Fortalecimiento de la atencion primaria de salud: propuestas para mejorar El sistema sanitario chileno. Temas de la agenda publica. Centro de Politicas Publicas. Pontificia Universidad Catolica de Chile 2014 https:// politicaspublicas.uc.cl/wp-content/uploads/2015/02/fortalecimientode-la-atencion-primaria-de-salud-propuestas-para-mejorar-elsistema-sanitario.pdf

24 Montero J, Tellez A, Herrera C. Reforma sanitaria chilena Y La atencion primaria de salud. Algunos aspectos criticos. Temas de la agenda publica. Centro de Politicas Publicas. Pontificia Universidad Catolica de Chile 2010.

25 MINSAL. Encuesta Nacional de Salud ENS Chile 2009-2010. Ministerio de Salud. Gobierno de Chile 2010.

26 Kitpinyochai T, Paisansudhi S, Washirasaksiri C, et al. Clinical outcomes of type 2 diabetic patients before and after attending Siriraj continuity of care clinic. J Med Assoc Thai 2013;96 Supp 2:S82-90.

27 O'Connor PJ, Desai J, Rush WA, et al. Is having a regular provider of diabetes care related to intensity of care and glycemic control? $J$ Fam Pract 1998;47:290-7.

28 Gulliford MC, Naithani S, Morgan M. Continuity of care and intermediate outcomes of type 2 diabetes mellitus. Fam Pract 2007;24:245-51.

29 Mainous AG, Koopman RJ, Gill JM, et al. Relationship between continuity of care and diabetes control: evidence from the third National health and nutrition examination survey. Am J Public Health 2004;94:66-70.

30 Parchman ML, Pugh JA, Noël PH, et al. Continuity of care, selfmanagement behaviors, and glucose control in patients with type 2 diabetes. Med Care 2002;40:137-44.

31 KT X. Usual source of care in preventive service use: a regular doctor versus a regular site. Health services research 2002;37:1509--29.

32 Lambrew JM, DeFriese GH, Carey TS, et al. The effects of having a regular doctor on access to primary care. Med Care 1996;34:138-51.

33 OECD. OECD health Statitics 2015, 2015. Available: http://www. oecd-ilibrary.org/social-issues-migration-health/data/oecd-healthstatistics/oecd-health-data-health-care-utilisation data-00542-en? isPartOf $=/$ content/datacollection/health-data-en

34 Kogan MDet al. The effect of gaps in health insurance on continuity of a regular source of care among preschool-aged children in the United States. JAMA 1995;274:1429-35.

35 Hemingway H, Saunders D, Parsons L. Social class, spoken language and pattern of care as determinants of continuity of carer in maternity services in East London. J Public Health 1997;19:156-61.

36 Donahue KE, Ashkin E, Pathman DE. Length of patient-physician relationship and patients' satisfaction and preventive service use in the rural South: a cross-sectional telephone study. BMC Fam Pract 2005;6:40--40.

37 Haggerty JL, Pineault R, Beaulieu M-D, et al. Practice features associated with patient-reported accessibility, continuity, and coordination of primary health care. The Annals of Family Medicine 2008;6:116-23. 10.1370/afm.802 [published Online First: 2008/03/12]

38 Adler R, Vasiliadis A, Bickell N. The relationship between continuity and patient satisfaction: a systematic review. Fam Pract 2010;27:171-8. 10.1093/fampra/cmp099 [published Online First: 2010/01/08]. 